Farum

Sociológico

\section{Forum Sociológico}

Série II

28 | 2016

Interculturalidade e educação

\title{
Interculturalidade e reflexão pedagógica em contexto de mudança social - Entrevista a Antonio Genovese
}

Interculturality and reflective pedagogy in times of social change - An interview with Antonio Genovese

\section{Antonio Genovese e Inês Vieira}

\section{OpenEdition}

Journals

\section{Edição electrónica}

URL: https://journals.openedition.org/sociologico/1373

DOI: 10.4000/sociologico.1373

ISSN: 2182-7427

\section{Editora}

CICS.NOVA - Centro Interdisciplinar de Ciências Sociais da Universidade Nova de Lisboa

\section{Refêrencia eletrónica}

Antonio Genovese e Inês Vieira, «Interculturalidade e reflexão pedagógica em contexto de mudança social - Entrevista a Antonio Genovese», Forum Sociológico [Online], 28 | 2016, posto online no dia 31 dezembro 2016, consultado o 29 março 2022. URL: http://journals.openedition.org/sociologico/1373 ; DOI: https://doi.org/10.4000/sociologico.1373 


\title{
INTERCULTURALIDADE E REFLEXÃO PEDAGÓGICA EM CONTEXTO DE MUDANÇA SOCIAL. ENTREVISTA A ANTONIO GENOVESE INTERCULTURALITY AND REFLECTIVE PEDAGOGY IN TIMES OF SOCIAL CHANGE. AN INTERVIEW WITH ANTONIO GENOVESE
}

\author{
Antonio Genovese \\ Università di Bologna, Dipartimento di Scienze Dell'Educazione "Giovanni Maria Bertin" \\ Inês Vieira \\ Universidade Nova de Lisboa (FCSH/UNL), Faculdade de Ciências Sociais e Humanas, Centro Interdisciplinar de Ciências \\ Sociais (CICS.NOVA)
}

Antonio Genovese é uma referência essencial na Pedagogia Intercultural italiana ${ }^{1}$, numa direcção de desenvolvimento da pedagogia crítica². Teve um papel pioneiro na criação de Centros de Documentação/Laboratórios de Educação Intercultural (CD/ $/ \mathrm{LEI})^{3}$ em Itália, onde se propõe o diálogo entre a escola, os serviços educativos e os actores sociais do território para o desenvolvimento integrado de objectivos interculturais. Com Andrea Canevaro 4 criou a revista Educazione Interculturale ${ }^{5}$, importante para a disseminação de boas práticas nesta área pedagógica.

Após uma longa experiência de docência universitária em História da Escola, Tecnologias Informáticas para a Aprendizagem e Pedagogia Geral, em 2000 tornou-se Professore Ordinario de Pedagogia Intercultural na Universidade de Bolonha. Leccionou, em vários cursos de licenciatura e mestrado integrado (até à sua aposentação, em 2013), Pedagogia Intercultural e da Interculturalidade, Pedagogia das Diferenças e da Mediação Intercultural.

Problematizou e mobilizou para os currículos dos cursos pedagógicos os debates sobre estereótipos, preconceitos, xenofobia, racismo, identidades e sentidos de pertença, conflitos culturais, educação global, anti-racista e intercultural, entre outros tópicos relativos aos grupos imigrantes e da segunda geração, de crescente importância no contexto italiano. Trabalhou, para além da interculturalidade e do multiculturalismo, sobre as temáticas dos conflitos e da violência, dos efeitos sociais e dos problemas educativos da globalização ${ }^{6}$.

Esta entrevista foi realizada no dia 19 de Maio de 2016 no Departamento de Educação da Universidade de Bolonha - lugar central na vida académica e pedagógica de Antonio Genovese - e faz parte de um diálogo mais longo entre entrevistado e entrevistadora?. Um diálogo de orientação e partilha de uma abordagem à interculturalidade na pedagogia e na investigação. A partir dele deu-se a aproximação entre os grupos de trabalho da UNIBO e do CICS. NOVA, marcada pelo projecto ALLMEET - Actions of Lifelong Learning Addressing Multicultural Education and Tolerance in Russia (co-financiado através do programa Tempus da União Europeia, 2013-2016). O projecto ALLMEET foi um dos pontos de partida para o presente número temático da revista Forum Sociológico sobre interculturalidade e educação.

Presta-se aqui homenagem e convida-se a centrar a atenção nas palavras de Antonio Genovese.

\section{História da interculturalidade}

Inês Vieira (IV) - Podemos começar por falar sobre a história do interculturalismo?

Antonio Genovese (AG) - Para fazer uma reflexão sobre a história da interculturalidade - eu falaria mais de interculturalidade que de interculturalismo, que é uma expressão menos utilizada em língua italiana.

\section{IV - Porquê?}

AG - Talvez porque, em italiano, o sufixo "-ismo" faz mais referência a movimentos. O multiculturalismo pode ser entendido como um movimento de pensamento com referência à multiculturalidade. $\mathrm{E}$ em Itália talvez não exista um movimento de pensamento tão compacto ao ponto de podermos falar de interculturalismo. Fala-se mais de interculturalidade porque, dos pontos de vista psicológico, sociológico, pedagógico, etc., não há um movimento assim tão forte... Ao passo que com o tema do multiculturalismo identifica-se não só uma realidade, mas sobretudo um pensamento sobre esta realidade.

A interculturalidade representa uma direcção de trabalho, uma perspectiva a realizar a partir da realidade social italiana que, nos últimos vinte anos, se transformou em sentido multicultural. 
Na realidade, Itália já era um país com profundas diferenças culturais bem antes da chegada de imigrantes: fortes diferenças sociais, entre o norte e o sul de Itália, diferenças de género, de acesso à cultura, etc. Porém, a expressão "multiculturalidade" só se usa desde a chegada a Itália, no final da década de 1980, de imigrantes estrangeiros à procura de trabalho.

\section{Mudança dos fluxos migratórios}

e da realidade social

Seguramente, se queremos falar de interculturalidade no mundo académico, devemos falar sobretudo a partir da realidade... Então... Para não nos alongarmos demasiado, proponho partir da II Guerra Mundial e das migrações que Ihe sucederam na Europa. Porquê a II Guerra Mundial? Porque provocou uma mudança radical: se, até à data, as migrações da Europa do Sul (Portugal incluído) se direccionavam aos Estados Unidos e à América do Sul, com o fim da II Guerra Mundial e a necessidade de reconstrução da Europa, em particular da Alemanha, inverte-se este fluxo. O que não significa que a migração acabe, mas a migração da Europa do Sul torna-se europeia. Em particular em direcção à Alemanha, mas não só, porque ao lado da reconstrução coloca-se todo o tema de "desenvolvimento" que se segue à II Guerra Mundial, por isso há uma migração de portugueses, espanhóis, italianos e gregos em direcção à Alemanha, a Inglaterra, a França... Este é um dado importante fundamentalmente até à década de 1960, porque com a descolonização e as lutas de libertação do "terceiro mundo" começa a abrir-se um outro fluxo migratório, sobretudo desde o norte de África até França, e dos países da Commonwealth até Inglaterra. Ao mesmo tempo, a Alemanha continua a ter um afluxo de migrantes provenientes do sul europeu.

Até à chegada dos imigrantes do norte de África e depois da Turquia, quais são as características da primeira migração, digamos, interna à Europa? Migrações laborais. Ou seja, migrações sobretudo no masculino, de jovens, ligadas a contratos de trabalho; acabados os contratos de trabalho, regresso a casa. Portanto, uma migração muito controlada. Isto verifica-se, em particular, na Alemanha, devido às baixas da II Guerra Mundial, com milhões de mortos, sobretudo jovens e homens, milhões de feridos, sobretudo soldados jovens e homens, mas também civis, e aqui acrescentamos mulheres. Para se reconstruir, a Alemanha precisava da mão-de-obra que chegava do sul europeu. E em geral, como ocorre na história das migrações, aquela migração apresentava-se como temporária, ligada a tipos específicos de trabalho, momentos particulares, mas sempre com a ideia de regresso a casa. Obviamente não é sempre assim - pense-se nos numerosos casamentos de homens sul europeus com mulheres alemãs, por exemplo - mas, em geral, creio que se pode dizer que se tratava de uma migração controlada e que, mais cedo ou mais tarde, resultaria em retorno ao país de origem.

Este traço, esta característica que é, precisamente, a característica de todas as migrações laborais, muda com a descolonização. Isto é, caem os regimes coloniais e quem deixa o próprio país - muitas vezes por estar ligado ao regime colonial - sai com toda a família. Por isso, em particular no caso francês - que considerava os territórios das colónias como territórios de ultramar, territórios franceses com leis francesas, com língua francesa, etc. -, no momento em que os países adquirem a própria liberdade e autonomia, França encontra-se na situação de ter no seu território "cidadãos franceses" que falam francês, mas também falam árabe, que têm características culturais diferentes, e por vezes com outras características somáticas, de tradição ou nos modos de vestir, de comer, etc. Por isso, começa a mudar radicalmente o quadro da migração, que já não pode ser considerada (apesar de também existir) migração laboral, porque se tornou uma migração que se quer estabilizar no país de chegada. Este traço começa a caracterizar a chegada de imigrantes dos países africanos também noutros países (como, imagino, tenha acontecido também em Portugal!), mas seguramente em Espanha, Itália e Grécia, a partir mais ou menos da década de 1980, em que este fluxo começa a ser observado.

Há que acrescentar, porém, que não desapareceu o fluxo contemporâneo de italianos no estrangeiro (e também de espanhóis, portugueses e gregos!), mas torna-se menos visível. Se olharmos para as estatísticas, até 2012 havia aproximadamente 5 milhões de imigrantes regulares em Itália, e ao mesmo tempo havia 5 milhões de italianos regularmente residentes no estrangeiro. Por isso, o fluxo migratório nunca foi interrompido. Porém, do ponto de vista da visibilidade social, ou seja de como a nova realidade social é percepcionada e reelaborada pelo senso comum, enquanto que o italiano no estrangeiro já não se vê, torna-se invisível até aos olhos dos italianos, começas a ver mais na tua rua, no cenário da tua cidade, que vive um estrangeiro diferente de ti, com hábitos diferentes, com modalidades de vida diferentes.

Mudança das respostas políticas e institucionais

A presença de imigrantes em Itália remonta aproximadamente à década de 1980, mas foi a partir da década de 1990 que se tornou um problema ao qual era necessário responder nos planos institucionais a diferentes níveis: político mas também social, escolar, etc. Em 1992 surgiu a primeira lei italiana 
para a migração, que procurava estabilizar a presença de imigrantes em Itália. Foi a primeira grande medida de legalização, ao atribuir a permissão de residência a quase todos os imigrantes indocumentados em Itália. Começamos, assim, a ter normas que regulam a presença de estrangeiros. Durante toda uma primeira fase, seguramente até à viragem do século, a ideia política prevalecente apontava para a possibilidade de existir uma migração laboral, de cidadãos estrangeiros regulares, homens ou mulheres, com um trabalho estável, um contrato de trabalho, uma casa. Ou seja, uma pessoa capaz de viver autonomamente, que não criava problemas de legalidade, e sob esta premissa era-Ihe atribuída a autorização de residência. De seguida - e também em relação ao que ia acontecendo noutros países europeus - introduziu-se em Itália a possibilidade de reagrupamento familiar, ou seja, um imigrante que vivesse aqui há um certo número de anos, com contrato de trabalho estável e habitação, tinha o direito de trazer para cá cônjuge e filhos.

É evidente que aqui encontramos dois cenários político-institucionais muito, muito diferentes. No primeiro caso tratava-se de dar o mínimo, ou seja, a habitação, o trabalho e algum tempo livre - e aqui a imigração em Itália era sobretudo masculina e esperava-se que terminasse com o retorno do imigrante ao seu país de origem. Por este motivo, por muito tempo permaneceu em vigor uma normativa que tinha como referência o imigrante jovem, que realiza um certo trabalho e que, após um determinado período, presume-se que regresse a casa. Por isso, do ponto de vista do que nos interessa ao nível de respostas sociais, essas eram muito baixas e muito, muito escassas.

O cenário muda completamente quando, em vez de migração laboral, passamos a lidar com uma migração (mais generalizada) da população, com a chegada de famílias. Neste caso já não chega o trabalho e a casa, começam a ser necessários serviços sociais, médicos, dirigidos também às famílias, e torna-se mais importante a possibilidade de celebrar a própria fé e credo religioso. Com a chegada dos filhos aumentam os pedidos de formação e nascem enormes problemas relacionais nas escolas, com conflitos frequentes entre pessoal escolar e famílias (pense-se, por exemplo, no problema do ensino da língua italiana a crianças nascidas no estrangeiro, ou no problema da alimentação para crianças muçulmanas, etc.). Neste novo cenário muda completamente o quadro dos pedidos feitos pelas comunidades estrangeiras, e nasce a necessidade do Estado italiano dar novas respostas a estes problemas novos e desconhecidos.

Em Itália foram criadas várias leis sobre estes temas, mas nunca houve uma linearidade, porque aos governos de centro-esquerda sucederam-se governos de direita e centro-direita, por isso houve sempre alterações consistentes nos objectivos e na normativa. Porém, o que se tentou fazer, tanto ao centro-esquerda como ao centro-direita, ainda que com muitas diferenças, foi alcançar uma "normalização do imigrante", através da criação de leis no âmbito das quais o imigrante se deve reger para ser considerado um imigrante regular no nosso país. Eu diria que mesmo os primeiros governos de centro-direita colocaram o problema da integração de quem estava cá com as suas famílias, com filhos que iam à escola com as crianças italianas, que brincavam com as crianças italianas, e colocou-se também o problema, muito sentido, da integração através da aprendizagem da língua italiana, sobretudo pela segunda geração. Para os imigrantes a língua era considerada importante, mas sobretudo para a vivência quotidiana, para poder fazer compras num supermercado, para falar com o empregador e com os colegas de trabalho, etc. Mas para as crianças e os jovens a perspectiva muda completamente, porque a língua não tem apenas uma função utilitarista, torna-se também a língua da vida quotidiana, dos afectos, da relação social, da possível integração social plena.

O mundo da imigração estrangeira começa, passo a passo, a estratificar-se e a diferenciar-se: por um lado o imigrante regular, por outro o imigrante indocumentado (muitas vezes próximo a formas ilegais); o imigrante que procura trabalho e quer retornar ao país de origem e o que trouxe para cá a sua família, projectando o seu futuro em Itália; o imigrante, primeira geração, que vive quase exclusivamente com os seus compatriotas e, por outro lado, a segunda geração que procura uma vida mais semelhante aos seus coetâneos italianos. Começam a vislumbrar-se mundos completamente diferentes e coloca-se, de maneira forte, consistente e substancial, o tema das possíveis formas de integração.

O desafio da integração em contexto de globalização

O que significa a integração nos planos social, educativo, relacional ou laboral? Quais os princípios em que se inspira? E aqui, em paralelo com estas mudanças, começa a nascer também o pensamento pedagógico intercultural. Diria que nasce como consequência das fortes mudanças sociais produzidas pela imigração.

Um outro elemento que coloco sempre neste quadro de mudança, que para mim é muito importante ainda que muitas vezes não tenha sido considerado como devia, é o tema da globalização. A migração tem sido vista simplesmente como consequência das condições económicas desastrosas dos países pobres, de um "ali não têm o que comer, por isso a fome e a falta de trabalho empurra-os para os países ricos, países onde se pode satisfazer a fome e 
há trabalho". Ou seja, em termos puramente económicos. Ao passo que o tema da imigração na era da globalização, se for observado nas suas dinâmicas complexas, não tem sentido (apenas) pelos aspectos económicos que se possam destacar, mas também pelos modelos e estilos de vida, pelos objectivos de relação social que são apresentados aos jovens em todos os ângulos do planeta. Quando os jovens africanos saem de África para virem para a Europa, não é apenas pela motivação de melhoria económica - claro que pode haver sempre esta dimensão -, é também porque já têm um estilo de vida muito semelhante aos jovens europeus, têm os mesmos mecanismos relacionais, ouvem a mesma música, vêem imagens semelhantes, com a televisão vêem os mesmos programas, têm as mesmas aspirações, a mesma vontade de bens de consumo.

Um campo de estudos que se observou em Itália, mas que depois foi um pouco esquecido, diz respeito à importância dos mass media. Em Itália tivemos, por volta da década de 1990, a chamada "invasão dos albaneses", mas se observarmos porque é que os albaneses saíam, não encontramos apenas a crise económica no país de origem; também constatamos que os albaneses viam a televisão italiana, aprendiam a falar italiano, tinham os modelos italianos. Lembro-me de falar com alguns jovens albaneses que me diziam: "Parecia que Itália era o país das utopias, onde tudo podia ser alcançado, e nós na Albânia não tínhamos nada; ir para Itália era ter bicicleta, mota, carro, ir dançar, viver, enfim!". Isto dá-te bem a ideia de não ser apenas o mecanismo económico a regular determinados fluxos e factores. É preciso estudar muito bem também os temas que dizem respeito à comunicação de massa, a tecnologia, os estilos de vida, as aspirações e desejos das pessoas. Eu diria que a globalização é um terreno em que as Ciências Sociais têm coisas a dizer e trazem um contributo importante ao conhecimento do fenómeno da interculturalidade.

\section{Pedagogia Intercultural e Ciências Sociais}

IV - E qual seria, então, o contributo da Pedagogia Intercultural para as Ciências Sociais?

AG - Partimos desta mudança no mundo - que não é apenas mudança de cenário, mas também de quem está no palco cénico - em que os actores sociais se encontram numa realidade, num cenário que mudou muito, e por isso todas as partes do guião que até agora tinham sido postas em cena já não são suficientes, é preciso mudar. Isto surge, a meu ver, em primeiro lugar no plano normativo, no plano jurídico, que certamente é um terreno muito importante, mas também surge no plano económico e no plano político. Mas, à medida que a migração se transforma numa migração estável, torna-se necessário observar outros temas e outras causas. Aqui (encontramos) o contributo da Pedagogia Intercultural, que partiu, como vimos, das relações educativas, e que permite analisar o tema dos conflitos. Não apenas os grandes conflitos sociais e económicos, mas também os conflitos relacionais, entre pessoas e grupos, que podem conduzir a violências, opressões e rupturas.

\section{Pedagogia para estrangeiros, integração} e anti-racismo

Dou um passo atrás para responder à tua pergunta: eu não falaria de "Pedagogia Intercultural", não há apenas uma Pedagogia Intercultural, há muitos pontos de vista. Um tema decisivo de diferenciação entre as diferentes abordagens é, a meu ver, o conflito, como se analisa e como se pensa geri-lo. Este é um tema muito importante.

Também em Itália se desenvolveu, com consistência e de modo difuso, ainda que nem sempre de forma explícita, uma "pedagogia para estrangeiros" (esta perspectiva educativa nasceu na Alemanha do pós-Guerra). O que é que os estrangeiros deviam fazer segundo esta perspectiva? Os estrangeiros deviam aprender a língua italiana, aprender as regras italianas, aprender como se vive aqui e estar cá "normalizando-se". E isto diz respeito não só à pedagogia como também à política, e, se formos ver os programas de todos os partidos de centro-direita, ainda hoje subsiste esta ideia. Existe a ideia de uma pedagogia especial e específica, diferenciada para os outros, em que o objectivo de fundo é: "tu vieste para cá, por isso deves tornar-te italiano, ponto final". E uma pessoa torna-se italiana estudando a língua, estudando a história, aceitando as normas, vivendo como se vive cá em Itália. Por isso, usas véu? Não, se estás cá deixas o véu em casa. És religioso? A religião é um facto pessoal que deves viver em casa. E assim se cria um conjunto de regras, todas orientadas para a assimilação.

Posteriormente nasceu um outro direccionamento pedagógico: o da integração social e relacional, que se baseia na valorização das diferenças. Aceitar as diferenças como um recurso, não só para o estrangeiro mas também para nós. Favorecer a capacidade de viver e de se confrontar com as diferenças: deste modo todos aprendemos mais alguma coisa, enriquecemos vivendo num mundo plural e globalizado. Não é uma escolha feita só a pensar nos estrangeiros, não é um idealismo ingénuo para que o estrangeiro esteja melhor, não; tens, digamos assim, um percurso educativo que é útil para o estrangeiro mas que também é necessário para ti, autóctone. Talvez seja útil sobretudo para ti, ao dar-te instrumentos para viveres num mundo globalizado. O programa Erasmus pode ser visto como um instrumento que te dá, a ti Inês, a possibilidade de conheceres uma parte da Europa, mas 
que também dá aos estudantes italianos (e a nós, Professores italianos!) mais uma possibilidade de aprendizagem: dá, a todos nós, uma nova possibilidade de nos transformarmos. Portanto, o intercâmbio Erasmus não é feito apenas para o estrangeiro que vem estudar para Itália; não, também é feito para que todos nós, italianos (estudantes e professores), tenhamos a possibilidade de conhecer outras culturas e de mudar os nossos pontos de vista!

Também neste percurso, digamos assim, direccionado para uma integração positiva, não assimilacionista, podemos identificar sumariamente duas perspectivas: a anglo-saxónica, estruturada em torno da educação anti-racista; e a francesa, precisamente a da interculturalidade. Portando, uma destas perspectivas começa a colocar muito em destaque - e bem, na minha opinião - o tema do racismo e dos preconceitos.

$\mathrm{Na}$ altura em que surgiu, houve um slogan francês que me tocou muito, de uma associação que se chamava SOS Racisme. O slogan dizia: "Combate o racista que... vive dentro de ti". E este, na minha opinião, é um ponto decisivo: o outro é racista? Talvez, é possível que aquele tipo seja racista. E tu? E eu, como sou? Este ponto de vista abre uma perspectiva pedagógica muito importante: o racismo, os preconceitos racistas partem dos indivíduos e podem, depois, manifestar-se de forma colectiva. Mas a raiz está dentro do indivíduo. $\mathrm{E}$ também dentro do pensamento de quem deve educar! É daqui que o trabalho educativo deve partir: de mim, educador, para poder perceber os preconceitos que os outros também têm!

\section{Compreender estereótipos, preconceitos e conflitos}

Esta análise dos preconceitos e dos estereótipos também se vê reforçada, nos dias de hoje, pelo contributo das Ciências Cognitivas, onde se estuda o tema "como é que conhecemos?". Para as Ciências Cognitivas o preconceito é algo que te ajuda na vida pessoal, por ser um modo de simplificarmos a nossa organização do conhecimento, para podermos ler a realidade que nos rodeia; não tem apenas um lado negativo. As Ciências Cognitivas ensinam-nos que a construção do nosso pensamento também se baseia na simplificação e na generalização, que são as características de fundo do preconceito. Por isso, todos nós somos portadores, muitas vezes inconscientemente, de preconceitos, porque a simplificação e a generalização são mecanismos que nos ajudam a construir o nosso pensamento!

Daí ser tão importante trabalhar para conter e contrastar os preconceitos, e este é seguramente um terreno de intervenção em que a Pedagogia Intercultural (ou, pelo menos, alguns sectores da Pedagogia Intercultural italiana e francesa) bebeu da educação anti-racista. Lembro-me do primeiro curso em que participei, como aluno e não como docente, precisamente sobre a pedagogia anti-racista. Neste curso faziam-nos trabalhar sobre todas estas temáticas, com uma série de exercícios de desempenho de diferentes papéis, exercícios cooperativos em que devias reflectir sobre ti mesmo e identificar os teus preconceitos - e, assim, fazer emergir o "teu ser racista".

Um outro nível que permite construir bases sólidas para uma Pedagogia Intercultural é a capacidade de enfrentar o preconceito do ponto de vista social, ou seja, como surge a transmissão social do preconceito: através dos amigos, da família, dos mass media, dos grupos de referência. A psicologia social coloca em evidência que os preconceitos presentes (de maneira mais ou menos consciente) no indivíduo encontram a sua legitimação no pensamento colectivo difundido em determinada realidade. Por exemplo, tu até podes pensar que "os negros são bons dançarinos", mas esta afirmação torna-se um preconceito quando se estabiliza e se generaliza, quanto "todos os negros" se tornam "bons dançarinos". Porque é que este pensamento se estabiliza e generaliza? Porque encontra uma legitimação social. Porque o amigo concorda, porque o pai também o diz, porque são coisas que ouviste dizer por pessoas nas quais confias, coisas que leste.

\section{A pedagogia como intervenção social}

É por isso que a Pedagogia Intercultural deve trabalhar sobre o indivíduo, mas não só sobre o indivíduo, também deve trabalhar sobre o contexto em que vive o indivíduo: sobre a escola, a família, o bairro, o grupo de amigos, a equipa de desporto... Começa a surgir uma ideia, digamos assim, um pouco mais aberta da educação: já não se olha apenas para a escola, para o processo educativo formalizado, institucionalizado, também se começa a olhar para todo o contexto de vida. O que se passa no bairro? Que lugares frequenta o jovem, a criança, etc. ? Como é a situação da família? Que relacionamentos tenho eu, professor ou educador, com a família? E por isso começas a alargar o olhar também para as profissões sociais: não importa apenas o professor, mas também o educador, o assistente social, o auxiliar de educação, o polícia, os funcionários das lojas, o pároco, etc.

Qual é o contributo da Pedagogia Intercultural? Colocar em evidência estas interconexões que existem entre as diferentes disciplinas e adquirir a consciência de que sozinhos não chegamos a lugar nenhum, que se não desenvolveres um pensamento complexo, que te permita enfrentar a complexidade, só vês uma pequena parte da realidade social e não consegues agir. A pedagogia não é só pensamento, também é acção, intervenção educativa, é necessário 
contar com o contexto familiar, com a situação do bairro, dos amigos, etc.

\section{A Pedagogia e os desafios políticos e institucionais}

É necessário considerar um terceiro ponto em que a Pedagogia pode dar um contributo, inspirando-se noutras disciplinas. Para uma acção educativa mais incisiva, e que se oriente sempre em direcção não-violenta, de relações positivas entre seres humanos e com o nosso planeta Terra (obviamente, do meu ponto de vista), também se coloca o tema político e institucional. Para explicar o que entendo por isto tomo como referência a tragédia do Holocausto, do nazismo e da situação dos judeus. Como é possível, perguntei a mim mesmo (mas não só eu, felizmente!), que a Alemanha, a Alemanha que na década de 1930 é o ponto mais avançado no mundo ocidental, por cultura científica, humanística, era o ponto máximo das capacidades industriais, o máximo de desenvolvimento cultural, económico, científico... como é possível que, precisamente naquele país, se tenha chegado a um ponto tal em que o outro (o diferente, o judeu) devesse ser anulado, apagado da Terra? Um conflito pode até ser violento, mas chegar à destruição completa do outro, porquê, como é possível?

Na minha opinião, foi possível devido ao processo de desumanização do outro. O outro deixou de ser humano. Mas como é possível que aquele ser que é como eu, que se aborrece, come, fala, até fala a mesma língua que eu, como é que se torna um ser não humano, um animal?

Para o compreender é preciso começar a pensar sobre o que era e porque surgiu esta mudança de significado e de percepção que se produziu no âmbito político, mas não só. Começou com o desenvolvimento de uma linguagem discriminante e "desumanizante": para os judeus já não se usavam termos humanos, começavam a usar-se termos animais (ratos, sanguessugas, ratazanas, aves de rapina, parasitas, carraças, etc.), porque esta linguagem devia conduzir a uma visualização daquela pessoa, o judeu, não como ser humano, mas como qualquer coisa de não humano. A política começou uma operação de desumanização, mas quem a continuou foram os mass media, a igreja, a ciência, a cultura, ou seja... a um certo ponto constituiu-se mesmo um círculo perverso e totalizante em torno deste pensamento discriminante. Por esse motivo, mesmo quem nunca tivesse visto um judeu na sua vida, começava a pensar que os judeus não eram seres humanos.
A Pedagogia em diálogo com as Ciências Sociais e Humanas

É um evento extremo, mas ajuda-nos a perceber a necessária relação da Pedagogia com outras ciências. Aqui, a Pedagogia não toca directamente o assunto, precisa de outras ciências. Precisa da História para perceber o que foi o nazismo e o holocausto. Precisa de investigação das Ciências da Comunicação para perceber que com o nazismo e o fascismo temos, pela primeira vez, um uso "moderno" dos meios de comunicação de massa. E precisa de outros elementos que dizem respeito à religião, elementos teológicos que permitam perceber como é que a religião se colocou face à questão dos judeus. Como é possível que a Igreja Católica tenha permanecido em silêncio face ao extermínio de um povo, um povo monoteísta, que adora o mesmo Deus único? O que se passou na história das religiões que tenha levado a isto? Obviamente, é preciso procurar conhecer também as dinâmicas sociais e relacionais.

Porque é que um povo inteiro, praticamente sem oposição, se convenceu de que os judeus deviam ser destruídos, que eram "as sanguessugas a depredar a pátria", porque é que se convenceram da superioridade dos alemães em relação a outros povos? Nenhum destes elementos pode ser analisado exclusivamente do ponto de vista educativo, há uma série de circunstâncias a estudar. A ciência! A ciência que chega ao ponto de justificar estas coisas! A ciência que chega ao ponto de dizer "sim, os judeus são seres inferiores por biologia"! Como é possível chegar a este ponto? Se observares estes temas apenas do ponto de vista educativo, perdes a complexidade da realidade e não consegues apreender como e porque é que surgem certos processos.

Os desafios presentes de uma Pedagogia Intercultural e "problematicista"

Há várias coisas que hoje me preocupam, que têm demasiados traços de semelhança com o que aconteceu na década de 1930. Por exemplo, os muros que se estão a construir na Europa. O que me faz ter medo é o pensamento que está por trás destes muros, um pensamento que não nasce numa terriola perdida que defende o próprio território e não quer outras presenças. Não, estamos a falar da Europa do século XXI, da Europa do terceiro milénio, onde tudo é superdesenvolvido: cultura, ciência, tecnologia, mass media... Porque é que se difunde um pensamento tão violento e discriminante? Creio que nos encontramos numa situação muito semelhante à que foi criada nas décadas de 1930/1940 na Europa, em que demasiadas instituições apontavam naquela direcção e muitas instituições permaneceram em 
silêncio, não falaram na linguagem que deveriam ter usado face a eventos deste tipo. Daí que se chegue a esta contraposição absurda, como se todos os problemas que vivemos hoje fossem imputáveis como no caso dos judeus - ao estrangeiro que cá chega, ao sírio, ao marroquino, ao africano.

Tomo como referência uma pedagogia que considero não só intercultural como também "problematicista". Um pensamento "problematicista" conduz-te na direcção da complexidade da realidade de hoje, face à necessidade de estes temas serem colocados de diferentes pontos de vista, de diferentes sectores, mas também de diferentes forças institucionais, culturais e políticas. Na minha opinião, sobretudo face às dinâmicas violentas que pudemos observar nos últimos anos, este é um ponto de vista muito importante: permite-te sair da fortaleza da educação entendida como apenas escola e processos formativos. Faz-te ver como a formação de hoje é uma acção que passa pela escola mas também pela família, pela internet, pelas instituições do bairro, pelos grupos desportivos, pelos mass media...

O contributo que a Pedagogia Intercultural pode dar é precisamente este: uma visão crítica que permite ao sujeito adquirir os instrumentos necessários para se orientar na realidade complexa. Ou seja, a capacidade de apreciar e gerir as diferenças culturais, os pontos de vista diferentes e por vezes até contrastantes, com um horizonte a meu ver irrenunciável, que é o da não-violência.

Se este horizonte se perde acabamos por chegar a conflitos que tendem a destruir o outro. Como diz um intelectual italiano que estimo muito, Gino Strada (presidente da Emergency), a guerra deve tornar-se um tabu, a guerra deve ser expulsa do pensamento humano, a violência deve ser expulsa do nosso pensamento. É possível? Talvez seja, talvez consigamos alcançar este objectivo se nos movermos numa direcção crítica e atenta ao mundo complexo e à cultura plural.

\section{As origens da Pedagogia Intercultural em Bolonha e em Itália}

IV - Como nasceu a Pedagogia Intercultural em Itália, e em Bolonha em particular?

AG - Em Bolonha eu diria que nasceu comigo e com o Andrea Canevaro. Inicialmente o Andrea deu-me muitas sugestões, muitas indicações. Mas, mesmo como disciplina académica, a ser chamada com a etiqueta de "Pedagogia Intercultural", nasceu porque eu quis ensinar estes temas na Universidade, e esta vontade foi aceite pelos meus colegas académicos. A denominação "Pedagogia Intercultural" era inexistente, foi preciso agir seja nos planos de estudo da Faculdade, seja a nível de Reitoria e, através das organizações pedagógicas académicas, também a nível nacional. Assim, fizemos com que fosse criado um corpo de estudos de "Pedagogia Intercultural" em quase todas as universidades italianas onde se ensinava Pedagogia, como parte da Pedagogia Geral.

Começámos a trabalhar sobre estes temas a partir da década de 1990. Em Itália, os primeiros docentes de Pedagogia Intercultural foram Concetta Sirna Terranova, Franca Punto Minerva, Agostino Portera, e em Bolonha eu, Stefania Lorenzini e Ivana Bolognesi.

Em Bolonha, para além da introdução da Pedagogia Intercultural na universidade, estivemos envolvidos na criação dos Centros de Documentação e Laboratórios (de formação) para a educação intercultural, com o objectivo de abrir a universidade aos problemas que começavam a emergir na escola e na sociedade.

Os primeiros pedidos de ajuda que nos chegaram à universidade foram feitos por professoras em pânico, que nos diziam: "Chegam à escola crianças marroquinas, tunisinas, que não sabem uma palavra de italiano. Não sabem falar, não sabem escrever, como é que lhes podemos ensinar italiano?".

Partimos destas necessidades e envolvemos grupos de docentes que ensinavam a língua italiana. Mas, ao mesmo tempo, começámos a colocar o problema da integração social, porque naquela altura, nas escolas, havia uma certa tendência em pedir turmas separadas para as crianças e jovens que não soubessem o italiano! Procurámos explicar aos professores que o ensino da língua italiana passa por uma boa socialização, e não pela separação! Experimentámos diferentes estratégias: em vez de separar os alunos, constituíram-se pequenos grupos em que os alunos italianos ensinavam algumas coisas aos colegas estrangeiros, e aos alunos estrangeiros pedíamos que falassem de si e do seu passado de modo a que as diferenças fossem valorizadas, e não convertidas em obstáculos. Foi um trabalho verdadeiramente difícil, porque os professores estavam apavorados com as mudanças radicais que observavam nas suas turmas.

\section{Um debate difícil em contexto de crise}

IV - Na sua opinião, quais são os principais desafios da interculturalidade no presente?

AG - A presença de estrangeiros em Itália tornou-se mais consistente e passou a colocar problemas mais graves, sobretudo para as classes sociais mais pobres, menos fortes ao nível socioeconómico. Pessoalmente, fazendo parte de uma classe social média-alta, não sinto a concorrência dos imigrantes no plano profissional, pelo contrário, sinto que o imigrante representa um recurso ao nível cultural, no trabalho e na minha rede de amigos. Noutras situações, a presença da migração muda não só o cenário, mas também os temas da própria 
vida. Há grupos sociais autóctones que, directa ou indirectamente, são atingidos pela crise económica e pela imigração. Quando trabalho em associações de voluntariado, em particular com italianos em situação mais débil, ouço várias vezes: "Mas porque é que o estado italiano tem de gastar tanto dinheiro com os imigrantes e com os refugiados políticos, e eu que estou desempregado, sou idoso, tenho uma reforma de $300 €$ por mês e tenho de viver assim? Porque é que aqueles recursos não são também para mim?". É claro que se tu estiveres numa situação de concorrência directa com o imigrante, que é mais pobre do que tu, torna-se difícil fazer-te compreender todas estas questões...

Há uma mudança muito radical das formas de vida, tanto que, hoje, todos entram em competição. Mas há quem seja directamente afectado por essa competição e há quem consiga extrair vantagens a partir dela. A qualidade de vida de alguns estratos sociais mudou e baixou muito, o que não se verificou noutros estratos. Hoje é necessário lidar com estas dinâmicas da realidade social, também na óptica do choque entre classes que, em determinadas áreas, se vêem em conflito.

\section{A globalização e os desafios de sustentabilidade}

Creio que o tema da globalização não foi tratado na profundidade em que deveria ser tratado. Ou seja: nós, "citadinos", somos sujeitos à globalização posta em acção pelo mundo económico, das finanças e da produção. Mas o "mercado livre mundial" está a mudar de maneira tão profunda a vida humana, o ambiente e outras dimensões, não só no Ocidente como também nos restantes países, que se torna difícil perceber para onde nos encaminhamos, quais os níveis de poluição, as transformações sociais, políticas, institucionais e culturais que vão surgindo. Tudo procede a uma velocidade que não te dá tempo para perceberes!

O tema de fundo é "aquilo que produz a globalização": é necessário ter um olhar ecológico, porque o teu bem pode significar muitos danos para os outros, e por isso é preciso encontrar um pensamento que origine situações novas e solidárias.

As dificuldades da educação intercultural

IV - Portanto, como desafio social em geral temos a globalização. E como desafio educativo?

AG - Como desafio educativo coloco, seguramente, o tema de aprender a conviver com a diversidade. Porque se não se conseguir aceitar as diferenças também não se é capaz de aceitar a igualdade de direitos. Não se consegue aceitar a humanidade do outro.

A chegada de refugiados políticos, o aparecimento do ISIS e as guerras fazem regredir as relações interculturais. Hoje, seguramente, é muito mais difícil trabalhar sobre estes temas. O medo do outro ganhou terreno e os conflitos aumentaram (não só em Itália mas em toda a Europa!).

Tenho a sensação de que a chegada de refugiados políticos mudou notoriamente a orientação da opinião pública. O refugiado político é sujeito a uma norma absurda: chega a Itália com a esperança de ir para outro país, mas depois tem de ficar cá. O tempo para reconhecimento ou não reconhecimento do seu direito a asilo é longuíssimo. Durante esse período não deve fazer nada, é mantido com fundos em parte provenientes da Europa, mas... Como dizia há pouco, que sentido é que isto tem para um reformado que lê o jornal e encontra o valor total, quanto se gasta?, $90 €$ por dia?, mas como se gasta tanto?, eh, $90 €$ por dia dão para ter um sítio para dormir, alimentação, formação, não os dás ao refugiado!, mas vai explicar isso às pessoas... Não há um instrumento para fazer compreender estas coisas.

E mais, com base nesta normativa absurda, os refugiados não podem fazer nada até que o seu estatuto seja reconhecido. Se o for, obviamente precisam de encontrar casa e trabalho, senão não podem ficar cá. Com a crise económica, onde é que encontras trabalho? Se o estatuto não for reconhecido, tens de ir embora - para onde? Não podem voltar para trás...

Foi montado um mecanismo absurdo, que age inclusivamente contra a migração económica. Porque aumenta notoriamente a competitividade com a imigração económica, ao mesmo tempo criando uma bolsa verdadeiramente preocupante de imigrantes em situação irregular que vivem nos limites da legalidade!

Ao mesmo tempo, na Europa crescem as forças políticas que alimentam os conflitos e apontam para soluções violentas.

IV - O que torna mais difícil a intervenção da ...

AG - Tudo isto torna muito mais difícil a reacção educativa. Até há alguns anos atrás eu recebia pedidos contínuos das escolas, associações, etc., para intervenções, conferências, encontros com professores. Nos últimos anos os pedidos diminuíram, apesar de ser cada vez mais necessário. Há mais necessidade de interculturalidade, de educação intercultural, de não-violência e de paz.

\section{Ser professor de Pedagogia Intercultural}

IV - Há alguma história importante na sua vida enquanto professor de Pedagogia Intercultural?

AG - Fazes-me viajar com a memória... Haveria muitas histórias a contar... Devendo escolher, tenho em mente duas, duas histórias. 
A primeira história. Optei sempre por dar aulas convidando os alunos a participar, partindo do que sabem, das suas competências, das suas sensações, enfim, dos seus pensamentos sobre todas estas questões. Uma vez, com um grupo consistente de alunos, falei de ciganos. Depois de termos feito uma parte do percurso em Pedagogia Intercultural, perguntei: "Quem são os ciganos? Que experiência têm com os ciganos?". Uma aluna conta que, na sua terra, num supermercado, estava uma mãe com a sua filha e, a um certo ponto, perde-a. A menina é procurada e descobre-se que uma cigana, que estava ali no supermercado, tinha escondido a menina sob a saia para a raptar. Esta história é absolutamente igual a outras histórias que já tinha lido e que me tinham sido contadas noutras situações. Deixei a aluna terminar o seu relato e perguntei: "Mais alguém conhece uma história semelhante?" - "Sim!", respondem vários alunos, "sei que aconteceu uma história parecida noutro sítio", e começam a contar.

Aí proponho-lhes que se organize um grupo de trabalho para estudar melhor o tema, incluindo uma consulta aos registos policiais sobre o rapto de crianças. Algumas aulas mais tarde o grupo diz-me: "Não há denúncias na polícia, nestes lugares não há denúncias, e nunca foi condenado nenhum cigano em Itália por rapto de criança".

No entanto, muitos se convencem de que os ciganos raptam crianças, e... assim se cria um mito urbano. A partir daqui discutimos preconceitos e estereótipos sobre ciganos, até chegarmos a esta conclusão: "Se tivéssemos à nossa frente um cigano, e se despoletasse o preconceito segundo o qual todos os ciganos roubam, pensaríamos que também esta pessoa seria um ladrão. Mas se conseguirmos conter este preconceito, devemos admitir que esta pessoa deve ser avaliada pelo que faz efectivamente, e não por pertencer a um certo grupo étnico!".

A segunda é a história da minha relação com os estudantes Erasmus. Considero esta história muito positiva. Nas minhas aulas, na faculdade, tive muitos alunos estrangeiros, e procurei sempre provocar o diálogo entre alunos estrangeiros e alunos italianos, de tal modo que surgisse um confronto com base em diferentes experiências e diferentes culturas. O objectivo era explicitar o olhar de jovens da mesma idade, de classe social semelhante, com o mesmo tipo de aculturação, a falar de Itália, dos italianos e dos seus próprios países. Era importante que cada um escutasse a voz dos outros e ouvisse como é que os outros nos vêem e nos julgam. Ou seja, como trabalhar estereótipos e preconceitos também entre jovens europeus!

\author{
IV - E que conselho daria a novos docentes e \\ estudantes de Pedagogia Intercultural? \\ AG - Diria que, em primeiro lugar, hoje deve-se
} reflectir sobre o tema da guerra e, como reflexo, para construir um horizonte positivo, o tema da não-violência. A guerra não destrói apenas as coisas, não polui apenas a realidade material, ela destrói verdadeiramente a humanidade, polui o nosso pensamento. Porque destrói os nossos sentimentos. Quando o outro se torna um inimigo, quando se constrói um inimigo... Deixa de se ver um ser humano, vemos apenas uma fera que é preciso matar. Que os motivos de um lado sejam mais fortes que do outro, que as razões do ocidente sejam mais fortes que as dos outros, conta relativamente. Mas o que mais conta é que o uso de armas, o uso da violência, conduz à desumanização. Talvez seja da velhice, mas hoje penso que a não-violência seja mesmo a estrada necessária. A não-violência leva-te, por outro lado, a pactos, negociações, mediações... Ou seja, leva-te à gestão do conflito de modo não violento, que é precisamente o mais necessário.

\section{Notas}

1 Como referência principal, Antonio Genovese (2003), Per una pedagogia interculturale, Bolonha, Bononia University Press.

2 Mariagrazia Contini e Antonio Genovese (1997), Impegno e conflitto. Saggi di pedagogia problematicista, Florença, La Nuova Italia.

3 Os Centros de Documentação/Laboratórios de Educação Intercultural (CD/LEI) apoiam o trabalho educativo com crianças e jovens imigrantes e de segunda geração, desempenhando um papel central na partilha de boas práticas da educação intercultural. O primeiro CD/LEI foi criado em Bolonha em 1992, resultado do protocolo entre a Câmara Municipal e a Província de Bolonha, os serviços escolares regionais e o Departamento de Educação da Universidade de Bolonha. Website http://www.comune. bologna.it/cdlei.

4 Andrea Canevaro é um autor de referência sobre os temas da integração e da educação na academia italiana, ao nível da pedagogia intercultural, mas sobretudo de pedagogia inclusiva (necessidades educativas especiais e diferentes capacidades).

5 Educazione Interculturale, website http://rivistedigitali. erickson.it/educazione-interculturale/.

6 Ver, por exemplo, Antonio Genovese (2005), "Sfide e conflitti della società multiculturale e globalizzata. Una lettura problematicista", in M. Contini (a cura di), Tra impegno e utopia. Ricordando Giovanni M. Bertin, Bolonha, Clueb; Antonio Genovese (2006), "Adozione internazionale e Pedagogia Interculturale. Modelli pedagogici di intervento e relazione", Ricerche di Pedagogia e Didattica; Antonio Genovese (2007), "Le cure educative nei contesti multiculturali. L'immagine sociale del genitore straniero", Ricerche di Pedagogia e Didattica; Antonio Genovese 
(2008), "Il soggetto nel mondo della globalizzazione", in E. Colicchi, Il soggetto nella pedagogia contemporanea, Una questione, un compito, Roma, Carocci.

7 A entrevista decorreu em italiano e foi posteriormente traduzida para português pela entrevistadora. O resultado que aqui se transcreve foi posteriormente revisto e aprovado pelos intervenientes. A estrutura da presente entrevista, previamente partilhada a pedido do entrevistado, baseava-se em quatro tópicos fundamentais: história da interculturalidade na academia italiana; referências e experiências pessoais; definição do campo intercultural e previsão do seu desenvolvimento; e reflexão sobre a prática pedagógica. Durante a entrevista prevaleceu o diálogo em detrimento de uma abordagem mais estruturada ao questionário de base. $\mathrm{O}$ registo dialogante definiu a forma deste documento, e, por sugestão do revisor, suscitou a necessidade de organizar o texto com subtítulos, categorias emergentes depois da transcrição e edição da entrevista, com revisão pelo entrevistado.

Recebido a 29/06/2016. Aceite para publicação a 07/10/2016.

Antonio Genovese (antonio.genovese@unibo.it). Università di Bologna, Dipartimento di Scienze Dell'Educazione "Giovanni Maria Bertin". Via Filippo Re, 6, Bolonha, Itália.

Inês Vieira (ines.vieira@fcsh.unl.pt). Universidade Nova de Lisboa (FCSH/UNL), Faculdade de Ciências Sociais e Humanas, Centro Interdisciplinar de Ciências Sociais (CICS.NOVA). Edifício I\&D, Avenida de Berna, 2, 1069-061 Lisboa, Portugal. 